\title{
DETERMINATION OF FERROUS IRON IN ROCK AND MINERAL SAMPLES BY THREE VOLUMETRIC METHODS
}

\author{
RISTO J. SAIKKONEN and IRJA A. RAUTIAINEN
}

\begin{abstract}
SAIKKONEN, RISTO J. and RAUTIAINEN, IRJA A. 1993. Determination of ferrous iron in rock and mineral samples by three volumetric methods. Bull. Geol. Soc. Finland 65. Part 1, 59-63.

Ferrous iron was determined by three volumetric methods in 13 in-house reference rock samples and in 31 international geological reference samples. The methods used were Amonette \& Scott's oxidimetric method, Wilson's oxidimetric method and Pratt's method. The results for $\mathrm{FeO}$ by these volumetric methods in 13 in-house rock samples were compared to the results obtained in other analytical laboratories in Finland. The results for $\mathrm{FeO}$ in the international samples were compared with published data. The results show that Pratt's method is the most reliable of the methods tested.
\end{abstract}

Key words: chemical analysis, methods, volumetric, ferrous iron, rocks, minerals.

Risto J. Saikkonen and Irja A. Rautiainen: Geological Survey of Finland. FIN2150 Espoo, Finland.

\section{INTRODUCTION}

The determination of ferrous iron $\left(\mathrm{Fe}^{2+}\right)$ in rock and mineral samples is important for geochemical and petrological investigations. The $\mathrm{Fe}^{2+}$ determination is often used together with the total iron determination to find the ferrous/ferric $\left(\mathrm{Fe}^{2+} / \mathrm{Fe}^{3+}\right)$ ratio of a sample. It is vital that both determinations are accurate if the $\mathrm{Fe}^{3+}$ content of a sample is obtained by deducting the ferrous iron from the total iron $\left(\mathrm{Fe}_{\text {tot }}\right)$ - both expressed as $\mathrm{Fe}_{2} \mathrm{O}_{3}$. The determination of total iron is reliable. $\mathrm{Fe}_{\text {tot }}$ is usually determined by X-ray fluorescence spectroscopy, atomic absorption spectroscopy or plasma-atomic emission spectrometry. The methods for determining ferrous iron can be divided into two principal types. In the first, decomposition is carried out by a boiling sulphuric-hydrofluoric acid mixture in a covered platinum crucible and the released $\mathrm{Fe}^{2+}$ is determined in the later step. In the other method, the $\mathrm{Fe}$ (II) ions are oxidized upon release by an oxidizing agent present in excess during the decomposition of the sample and the excess then determined (Johnson and Maxwell 1981). Ferrous iron in the solution is measured by volumetric, spectrophotometric, polarographic or ion chromatographic methods (Rice 1982, Bruce et al. 1987, Kiss 1987, Moore 1979, Kanai 1990).

In the laboratory of the Geological Survey of Finland a precise, accurate and fast method is needed to analyze large batches of samples. For this purpose we have compared the existing titration methods for analysis of ferrous iron for 13 in-house rock samples and 31 intemational geological samples. In Amonette \& Scott's method and in Wilson's method the decomposition of the sample is conducted in the presence of an oxidizing agent (Amonette and Scott 1990, Wilson 1955, Whipple 
1974). In Pratt's method no oxidizing agent is used during the decomposition (Maxwell 1968). The results for $\mathrm{FeO}$ by the volumetric methods in 13 inhouse rock samples were compared with the results obtained in other analytical laboratories in Finland. The results for $\mathrm{FeO}$ in 31 international geological samples were compared with data published in Geostandards Newsletter 13, Special Issue (Govindaraju 1989).

\section{EXPERIMENTAL}

\section{Amonette and Scott's method}

The sample was decomposed by the mixture of sulfuric and hydrofluoric acids containing a known amount of vanadium pentoxide in the tightly closed polypropylene bottle at $60^{\circ} \mathrm{C}$ for 4 hours. Standardized ferrous ammonium sulphate was added, and the excess of the Fe(II) was titrated with standardized ammonium metavanadate. The rapid additions of redox reagents were made using manual dispensers and the quantification of these additions was made by gravimetry. The same bottle was used throughout the entire process (Amonette \& Scott 1991).

The procedure was as follows: $0.1-0.2 \mathrm{~g}$ of the powdered rock sample was weighed into a $150 \mathrm{ml}$ polypropylene bottle. The bottle was tared, $20 \mathrm{ml}$ $0.030 \mathrm{M} \mathrm{NH}_{4} \mathrm{VO}_{3}$ in $4.5 \mathrm{M} \mathrm{H}_{2} \mathrm{SO}_{4}$ (standardized with ferrous ethylenediammonium sulphate) was added and the bottle was reweighed. Five $5 \mathrm{ml} 38 \%$ $\mathrm{HF}$ was added and the bottle was tightly closed and put in a $60^{\circ} \mathrm{C}$ water bath. The decomposition time was 4 hours. The bottle was let to cool to room temperature and the outside of the bottle was dried with a paper towel. Twenty $\mathrm{ml} \mathrm{5 \%}$ boric acid solution and $20 \mathrm{ml} 3.7 \mathrm{M} \mathrm{H}_{3} \mathrm{PO}_{4}$ was added. The bottle was tared, $20 \mathrm{ml} 0.0310 \mathrm{M} \mathrm{Fe}\left(\mathrm{NH}_{4}\right)_{2}\left(\mathrm{SO}_{4}\right)_{2}$ in $4.5 \mathrm{M} \mathrm{H}_{2} \mathrm{SO}_{4}$ was added and the bottle was reweighed. The excess of the $\mathrm{Fe}(\mathrm{II})$ was titrated with standardized $0.030 \mathrm{M} \mathrm{NH}_{4} \mathrm{VO}_{3}$ solution to a violet color using $0.2 \% \mathrm{Ba}$-diphenylamine sulphonate solution as indicator. The densities of the $\mathrm{Fe}(\mathrm{II})$ and $\mathrm{V}(\mathrm{V})$ solutions were determined by weighing in a tared $100 \mathrm{ml}$ volumetric bottle.

\section{Wilson's method}

The sample was decomposed by hydrofluoric acid containing a known amount of vanadium pentoxide in the covered (not tightly) polypropylene bottle at room temperature overnight. The addition of ferrous ammonium sulphate was made and the excess of $\mathrm{Fe}$ (II) was titrated with potassium dichromate (Wilson 1955, Whipple 1974).

The procedure was as follows: 0. 1- 0.2 g of the powdered rock sample was weighed into a $150 \mathrm{ml}$ polypropylene bottle. Exactly $5 \mathrm{ml} 1 \mathrm{~N} \mathrm{NH}_{4} \mathrm{VO}_{3}$ solution and about $10 \mathrm{ml} 38 \% \mathrm{HF}$ was added. The covered bottle (not tightly) was allowed to stand overnight. $10 \mathrm{ml}$ of the $\mathrm{H}_{2} \mathrm{SO}_{4}: \mathrm{H}_{3} \mathrm{PO}_{4}: \mathrm{H}_{2} \mathrm{O}$ mixture (1: 2: 2) was added and the contents of the bottle were then poured into $100 \mathrm{ml}$ of $5 \%$ boric acid solution in a $400 \mathrm{ml}$ beaker. The bottle was rinsed with an additional $100 \mathrm{ml}$ of boric acid solution. Exactly $10 \mathrm{ml} 0.05 \mathrm{~N} \mathrm{Fe}\left(\mathrm{NH}_{4}\right)_{2}\left(\mathrm{SO}_{4}\right)_{2}$ solution was added. The excess of the $\mathrm{Fe}$ (II) was titrated with $0.05 \mathrm{~N} \mathrm{~K}_{2} \mathrm{Cr}_{2} \mathrm{O}_{7}$ solution (standardized with ferrous ammonium sulphate) to a violet color using $0.2 \%$ Ba-diphenylamine sulphonate as indicator.

\section{Pratt's method}

The sample was decomposed by a mixture of boiling sulfuric and hydrofluoric acid in a covered platinum crucible at atmospheric pressure with air excluded by steam. The released Fe(II) was titrated with potassium dichromate (Maxwell 1968).

The procedure was as follows: $0.3-0.5 \mathrm{~g}$ of the powdered rock sample was weighed into a $30 \mathrm{ml}$ platinum crucible and $10 \mathrm{ml} 6 \mathrm{M} \mathrm{H}_{2} \mathrm{SO}_{4}$ was added. The covered crucible was placed onto the sand bath at $100^{\circ} \mathrm{C}$ and the contents of the crucible were boiled for two minutes. $10 \mathrm{ml} \mathrm{38 \%} \mathrm{HF} \mathrm{was} \mathrm{added}$ and the contents were boiled for ten minutes. $50 \mathrm{ml}$ $5 \%$ boric acid solution, $50 \mathrm{ml} 6 \mathrm{M} \mathrm{H}_{2} \mathrm{SO}_{4}$ and $40 \mathrm{ml}$ $9 \mathrm{M} \mathrm{H}_{3} \mathrm{PO}_{4}$ were added to $400 \mathrm{ml} \mathrm{H}_{2} \mathrm{O}$ in a $600 \mathrm{ml}$ beaker. The crucible was immersed below the 
surface of the acid solution. The Fe(II) was titrated with $0.05 \mathrm{~N} \mathrm{~K}_{2} \mathrm{Cr}_{2} \mathrm{O}_{7}$ solution (standardized with ferrous ammonium sulphate) to a violet color using $0.2 \%$ barium diphenylamine sulphonate as indicator. If any dark undecomposed residue was left, the procedure described was repeated.

\section{RESULTS AND DISCUSSION}

\section{Precision and accuracy}

The precision of the three volumetric methods was evaluated from the results by 10 re-determinations of in-house rock samples RS 101, RS 81 and RS 31 (Table 1). The relative standard deviations of Amonette \& Scott's method were $0,8 \%, 5,7 \%$ and $10 \%$, when the results for $\mathrm{FeO}$ were $8,43 \%, 1,76 \%$ and $0,40 \%$, respectively. Analogously the relative standard deviations in Wilson's method were 3\%, $4 \%$ and $20 \%$, and in Pratt's method $1 \%, 7 \%$ and $25 \%$, respectively (Table 1 ).

The $\mathrm{FeO}$ values determined by Amonette \& Scott's method and by Wilson's method for inhouse rock samples were almost all higher (except for samples RS 11 and RS 71 by Amonette \& Scott's method and for sample RS 91 by Wilson's method) than the values determined in three other analytical laboratories in Finland (Table 1). The results by Amonette \& Scott's method with the longer dissolution procedure A2 were higher than those with the normal dissolution procedure $\mathrm{Al}$ (Table 1). The results obtained by Pratt's method were consistent with the results of the three other laboratories (Table 1).

Our $\mathrm{FeO}$ values determined by Amonette \&

Table 1. FeO values determined by three volumetric methods for 13 in-house rock samples in the present study. Results of three other analytical laboratorien in Finland. $n=$ number of determinations. $N=$ number of other laboratories. Sulphur determined using Leco analyzer.

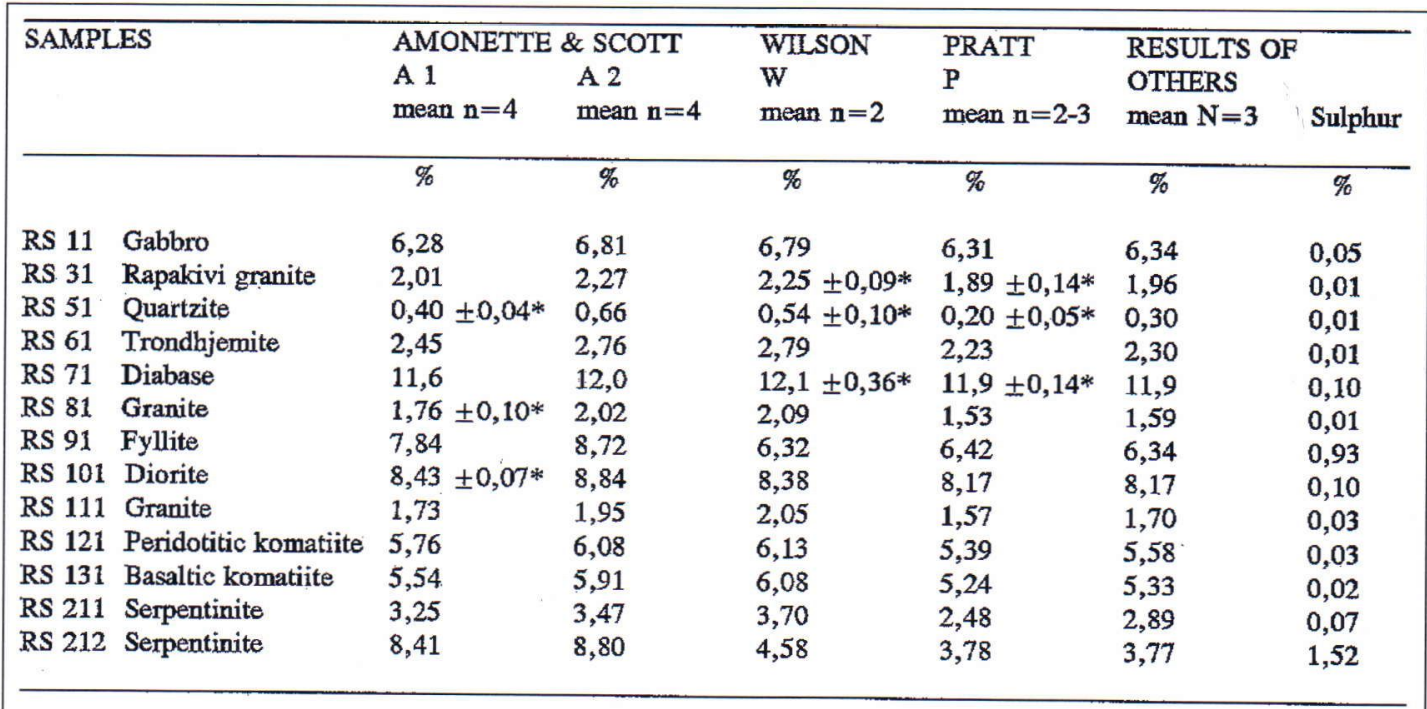

A 1 : sample dissolution at $60^{\circ} \mathrm{C}$ for $4 \mathrm{~h}$ in the tightly-capped bottle.

A 2 : sample dissolution at $60^{\circ} \mathrm{C}$ for $4 \mathrm{~h}$ and at $25^{\circ} \mathrm{C}$ overnight in the tightly-capped bottle.

W : sample dissolution at room temperature overnight in the covered (not tightly) bottle.

$\mathrm{P}$ : sample dissolution at $100^{\circ} \mathrm{C}$ for $10 \mathrm{~min}$ at atmospheric pressure with air excluded by steam.

* : 10 replicate determinations. 
Table 2. FeO values determined by three volumetric methods for 31 geological reference samples. Recommended $\mathrm{FeO}$ and $\mathrm{S}$ values from the literature. $n=$ number of determinations.

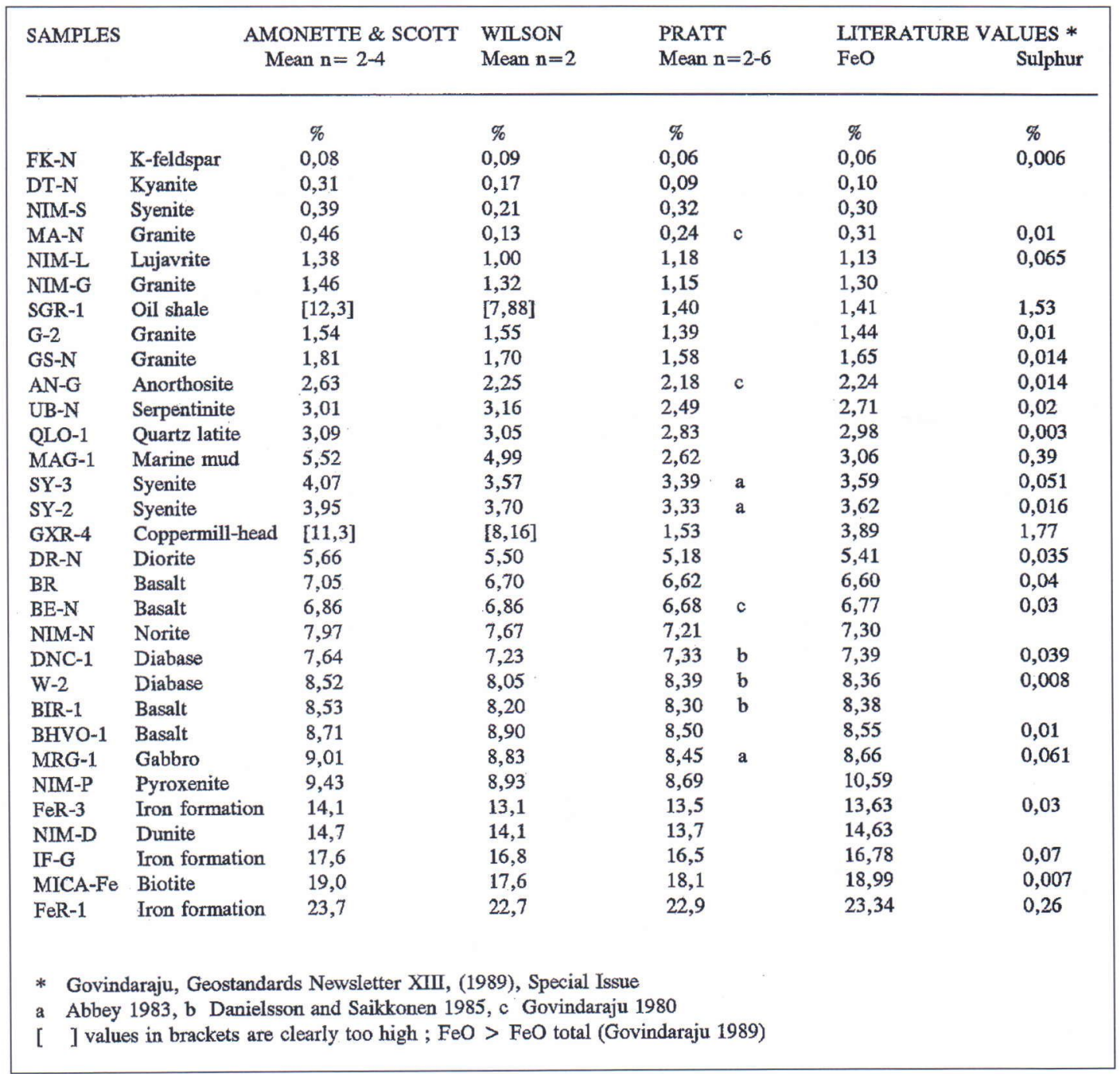

Scott's method for international geological reference samples were almost all higher (except for the sample NIM-P) compared to the values in the literature (Table 2).

The agreement of our $\mathrm{FeO}$ with the values in the literature was excellent $( \pm 0-3 \%)$ for 7 samples, good ( $\pm 3-10 \%)$ for 10 samples, reasonable $( \pm 10$ $20 \%$ ) for 4 samples and poor (>20\%) for 10 samples.

The agreement of our $\mathrm{FeO}$ values determined by
Wilson's method with the values in the literature was excellent ( \pm 0-3\%) for 14 samples, good $( \pm 3$ $10 \%)$ for 7 samples, reasonable ( $\pm 10-20 \%)$ for 3 samples and poor $(>20 \%)$ for 7 samples (Table 2 ).

The agreement of our $\mathrm{FeO}$ values determined by Pratt's method with the values in the literature was excellent $\pm 0-3 \%$ ) for 14 samples, good-( $\pm 3-10 \%)$ for 13 samples and reasonable $( \pm 10-20 \%)$ for 4 samples (Table 2). 


\section{INTERFERENCES}

The problems associated with the determination of the ferrous iron begin with the preparation of the sample. Atmospheric oxidation of ferrous to ferric iron and contamination of the sample from the grinding materials may occur during grinding of the sample (Sulcek and Povondra 1989, Whipple et al. 1984). In Amonette \& Scott's and in Wilson's procedure the aerial oxidation of ferrous iron during decomposition of the sample is eliminated by immediate oxidation of ferrous ions by a known amount of vanadium pentoxide (Amonette \& Scott 1991, Wilson 1955, Whipple 1974). In Pratt's procedure the air is excluded by steam during the decomposition of the sample (Maxwell 1968). It was not possible to study these complications in the present work.

The three methods used for $\mathrm{FeO}$ determination may involve some other sources of error causing high or low ferrous values. The erroneous results for the $\mathrm{FeO}$ concentration in the sample may result from:

(A) The sulphur(II) in soluble sulphide minerals in a sample will reduce some of the Fe(III) present. This may result in a high $\mathrm{Fe}(\mathrm{II})$ value. This interference will be greater if acid decomposition is carried out in the closed system (Tables 1 and 2). The oxidation of $\mathrm{S}^{2-}$ to $\mathrm{S}^{6+}$ has the capacity to reduce any $\mathrm{Fe}^{3+}$ present to give an apparent $\mathrm{FeO}$ equivalent to about 14 times the weight of S(II) present. Thus even $0.01 \%$ of sulphur could increase the iron(II) oxide concentration by up to $0.18 \%$ of $\mathrm{FeO}$ if the decomposition is carried out in closed system. It is not known to what extent reduction of iron ${ }^{3+}$ will occur in Amonette \& Scott's and in Wilson's procedure but this increase in $\mathrm{FeO}$ concentration is predictable, e.g.,for sample RS 212 (Table 1) and for samples SGR-1 and GXR-1 (Table 2) in the present work. In Pratt's procedure most of the soluble $\mathrm{S}$ (II) is lost as hydrogen sulfide gas during the acid decomposition in the platinum crucible.

(B) Some iron-bearing minerals are refractory, e.g., chromite, magnetite, ilmenite, tourmaline, some garnets and staurolite. They dissolve slowly or not at all in three procedures in the present work. In Amonette \& Scott's method it is possible for some refractory minerals to stand up to 24 hours at $60^{\circ} \mathrm{C}$ and in Wilson's method to several days at room temperature (Amonette \& Scott 1991, Wilson 1955, Whipple 1974). Prolonged boiling in hydrofluoric acid may dissolve more of these minerals in Pratt's procedure; however, hot sulphuric acid promotes oxidation of $\mathrm{Fe}^{2+}$ (Johnson and Maxwell 1981). Samples NIM-P and NIM-D (Table 2) contain chromite (Sulcek and Povondra 1989).

(C) Other species cause oxidation or reduction of iron during the decomposition of the sample. Elements that are present in the sample in lower oxidation states, e.g., vanadium(II), titanium(III) and tungsten(III), cause high results for ferrous iron because they either reduce any iron(III) that is released during the sample decomposition or because they are also oxidized by the vanadium pentoxide and the potassium dichromate. Elements that are present in upper oxidation states, e.g., manganese(IV) and vanadium(V), cause low results. Most organic substances may reduce the titration solution and cause considerable errors. Metallic iron, if introduced into the sample during the grinding process, causes high results for ferrous iron, because it is converted to ferrous sulphate during the sample decomposition (Johnson and Maxwell 1981, Sulcek and Povondra 1989).

\section{CONCLUSIONS}

In the determination of ferrous iron the analysis technique generally has less influence on the apparent speciation than does the sample matrix. The volumetric methos used in the present work are applicable to determination of Fe(II) concentration in many rock and mineral samples, if the samples are acid soluble. Some components in the sample matrix cause interference and it seems that Amonette \& Scott's method and Wilson's method are not accurate in the presence of sulphide minerals, which are attached by the used acid mixtures. It is difficult 
to explain the reason for some differences between the $\mathrm{Fe}$ (II) values by the three volumetric methods and the values in the literature. For unknown samples the most reliable of the methods studied is Pratt's method.

\section{REFERENCES}

Abbey, S., 1983. Studies in "standard samples" of silicate rocks and minerals, 1969-1982. Geological Survey of Canada, Paper 83-15.

Amonette J.E. and Scott, A.D., 1991. Determination of ferrous iron in non-refractory silicate minerals. 1. An improved semi-micro oxidimetric method. Chemical Geology 92, 329-338.

Bruce, C. B. and Bower, N.W., 1987. Spectrophotometric determination of ferrous iron in eighteen United States geochemical reference standards. Geostandards Newsletter 11, 41-42.

Danielsson, $R$. and Saikkonen, $R$., 1985. Chemical analysis of USGS-W-2, USGS-DNC-1 and USGS-BIR-1 standard rocks. Geological Survey of Finland. Report of investigation 70 .

Govindaraju, K., 1980. Report (1980) on three GITIWG rock reference samples. Geostandards Newsletter 4, 49-138.

Govindaraju, K., 1989. 1989 Compilation of working values and sample description for 272 geostandards. Geostandards Newsletter 13. Special Issue.

Kiss, E., 1987. Micro-fusion and spectrophotometric determination of iron(II) and iron(III) in chrome spinels
ACKNOWLEDGEMENTS: We are indebted to Mrs Riitta Juvonen, Dr Tapio Koljonen and Mr Esko Kontas for critically reading the manuscript. We also wish to thank Mrs Carola Eklundh for revising our EngIish.

and other refractories. Analytica Chimica Acta 193, 315-323.

Johnson, W.M. and Maxwell J.A., 1981. Rock and Mineral Analysis. John Wiley and Sons, New York. 184192.

Maxwell, J.A., 1968. Rock and Mineral Analysis, Interscience, New York. 324-326.

Moore, W. M., 1979. Voltametric determination of Iron(II) and Iron(III) in Standard Rocks and other Materials. Analytica Chimica Acta 105, 99-107.

Rice, T.D., 1982. Determination of Iron(II) in Silicates by Gravimetric Titration. Analyst 107, 47-52.

Sulcek, Z. and Povondra, P., 1989. Methods of Decomposition in Inorganic Analysis. Boca Raton, Florida, CRC Press, Inc. 44-54.

Whipple, E.R., 1974. A study of Wilson's determination of ferrous iron in silicates. Chemical Geology 14, 223-238.

Whipple, E.R., Speer, J.A. and Russel, C.W., 1984. Errors in $\mathrm{FeO}$ determinations caused by tungsten carbide grinding apparatus. American Mineralogy 69, $987-$ 988.

Wilson A.D., 1955. A new method for the determination of ferrous iron in rocks and minerals. Bulletin of the Geological Survey of Great Britain 9, 56-58. 